\title{
Pastoreio e hospitalidade do Senhor Exegese do Salmo 23
}

\author{
Matthias Grenzer *
}

\section{Resumo}

Uma pessoa religiosa, diante da perseguição, sente-se protegida por Deus: eis o que o Salmo 23 descreve. Metaforicamente, um animal - e não o rebanho! - experimenta, de forma surpreendente e duradoura, o pastoreio e a hospitalidade do Senhor, Deus de Israel, embora não falte quem insiste na agressão. O presente estudo propõe-se a realçar a beleza literária deste poema bíblico, assim como os pormenores da reflexão teológica promovida por meio dele.

Palavras-chave: Salmos, Espiritualidade Bíblica, Pastor, Anfitrião.

\footnotetext{
* Dedico este estudo às Irmãs de Santa Catarina em Frankfurt, na Alemanha. Em especial agradeço as Irmãs Martina e Ursula, por terem sido tão hospitaleiras comigo, na ocasião das minhas diversas estadas em Frankfurt, a fim de aproveitar Biblioteca da Faculdade de Filosofia e Teologia St. Georgen. Também esta pesquisa nasceu ali.

Ich widme diesen Aufsatz den Katharinenschwestern in Frankfurt am Main, Deutschland. In besonderer Weise danke ich den Schwestern Martina und Ursula für ihre Gastfreundschaft während meiner verschiedenen Aufenthalte in Frankfurt. So war es mir möglich, immer wieder die Bibliothek der Philosophisch-Theologischen Hochschule St. Georgen zu benutzen. Auch dieser Aufsatz ist dort entstanden.
} 


\section{Zusammenfassung}

Es gibt die religiöse Erfahrung, dass ein verfolgter Mensch sich von Gott beschützt fühlt. Psalm 23 beschreit just dieses Ereignis: ein Tier - und nicht die Herde! - erfährt überraschend und andauernd das Weiden und die Gastfreundschaft des Herrn und Gottes Israels, obwohl es nicht an Agressoren mangelt. Die hier vorgelegte Studie versucht die literarische Schönheit und die Einzelheiten der theologischen Reflektion dieses biblischen Gedichts hervorzuheben.

Stichwörter: Psalmen, Biblische Spiritualität, Hirte, Gastgeber.

\section{Introdução}

O Salmo 23 é um dos textos bíblicos mais populares. Pendurado em paredes de salões de beleza, sorveterias, oficinas e lares de famílias, esta oração bíblica acompanha as pessoas em seu dia a dia. Embora existam centenas de outras orações bíblicas, as palavras do Salmo 23, facilmente, ganham a preferência quando alguém está à procura de conforto espiritual. Como se justifica que o Salmo 23 se tornou tão simpático e acessível a tantas pessoas? E, em contrapartida: será que o Salmo 23 não corre o risco de uma "prematura espiritualização" e de uma "leitura exangue"?"

Uma razão para a preferência talvez se encontre na circunstância de a oração ser relativamente curta. Seis versículos apenas. Na versão hebraica, cinquenta e seis palavras, ou seja, oito vezes sete, sendo que o número sete serve, aos poetas hebreus, como elemento estilístico. Com um mínimo esforço, o leitor decora as palavras do Salmo 23.

Outro motivo da simpatia cultivada pelo Salmo 23, provavelmente, esteja ligado às duas imagens no poema. Na primeira parte do texto, o Senhor, Deus de Israel, é apresentado como pastor (v. 1b-4). Na segunda parte, o mesmo Deus é mostrado como anfitrião (v. 5-6). Não são imagens simples, mas são retratos compostos por diversos elementos. Dessa forma, as metáforas prendem a atenção de seus leitores por mais tempo. Além disso, por mais que o trabalho do pastor e o cultivo da hospitalidade, na perspectiva original do

$\overline{{ }^{1} \text { Luís Alonso-Schökel }}$; Cecília Carniti, Salmos I, p. 380. 
Salmo 23, tenham seu lugar no contexto geográfico-cultural do Antigo Israel e do Antigo Oriente em geral -, as realidades do pastoreio e da hospitalidade, assim como suas conotações simbólicas, atravessam os séculos e continuam a ser acessíveis. Neste sentido, "o Salmo tornou-se um formulário, no qual cada indivíduo insere seus dados pessoais, [...] a fim de o poema realizar, de forma admirável, um processo de condensar e concretizar a experiência e o sentimento de vida de muitos". 2

Contudo, a beleza literária do Salmo 23 não se limita às duas imagens criadas pelo autor, a fim de descrever a atuação do Senhor. O poema revela ainda o uso de outros recursos retóricos e estilísticos. Pode ser observada, por exemplo, uma estrutura concêntrica. Tal composição artística torna-se visível quando se descobre a direção do discurso de quem levanta, poeticamente, sua voz. Ao se apresentar como indivíduo, pois, o salmista dirige-se, no início (v. 1b-3) e no final (v. 6), à comunidade de seus ouvintes, para lhe falar sobre o comportamento do Senhor. É um primeiro tipo de diálogo. Centralmente, por sua vez, num segundo tipo de diálogo, o salmista propõe-se a falar, diretamente, ao Senhor, seu Deus (v. 4.5). É provável que essa circunstância - quer dizer, o fato de o Salmo 23 apresentar um discurso individual de quem se dirige ora aos outros ora a Deus - favoreça, outra vez, o acolhimento dessa oração bíblica pelas pessoas, sobretudo quando estas querem expressar, de forma individual, sua reflexão religiosa. Em geral, pois, prevalece uma ambivalência entre o diálogo com as outras pessoas e um direcionamento direto da palavra a Deus.

Aliás, justamente o aspecto da individualidade destaca, mais uma vez, o Salmo 23 e torna-se, provavelmente, outro motivo da preferência por esse poema. Quer dizer: enquanto a imagem do pastor (divino) e do gado miúdo ou do rebanho (cf. S1 80,2; Is 40,11; Jr 31,10; Ez 34,11-16; Mq 7,14) é comum e tradicional, o Salmo 23 aliena a metáfora que visa ao coletivo. Identifica-se, ao contrário, com um só animal e descreve a atuação do pastor a partir da experiência de vida feita por este animal. ${ }^{3}$ De certa forma, tal visão corresponde às palavras do pastor divino em Ez 34,15: Procurarei pela (ovelha) que se perdeu, farei voltar a que se dispersou, enfaixarei a que se quebrou e fortalecerei a que se retorce de dores; a gorda e forte, porém, destruirei - pastoreá-la-ei segundo $o$ direito. Também neste discurso, prevalece, no que se refere ao animal, uma perspectiva individual. Todavia, "que um indivíduo confessa o Senhor ser seu pastor acontece unicamente no Salmo 23 e em Gn 48,15".4

\footnotetext{
${ }^{2}$ Manfred Oeming, Das Buch der Psalmen, p. 155.

${ }^{3}$ Klaus Seybold, Poetik der Psalmen, p. 207.

${ }^{4}$ Regine Hunziker-Rodewald, Hirt und Herde, p. 172.
} 
Enfim, ganha visibilidade a circunstância de que o Salmo 23, "de um modo extraordinário, foi artisticamente elaborado". ${ }^{5} \mathrm{O}$ texto não quer ser lido somente de forma linear, ou seja, do início ao fim. Ao apresentar uma estrutura concêntrica (a-b-b'-a'), o poema precisa ser lido também "das margens rumo ao centro". ${ }^{6}$ De certo, somente uma leitura atenta é capaz de evidenciar os elementos estilísticos utilizados pelo poeta, a fim de formar as unidades literárias menores de seu poema e criar as ligações necessárias entre elas. $\mathrm{O}$ presente estudo propõe-se a evidenciar tais pormenores. Neste sentido, apresenta, de forma antecipada, um pequeno esquema, o qual procura visualizar a estrutura presente no Salmo 23, a fim de facilitar a leitura e a compreensão do poema bíblico.

v. 1b-3: o salmista fala sobre o Senhor, dirigindo-se a seu ouvinte

v. 4: o salmista dirige-se, diretamente, ao Senhor

v. 5: o salmista dirige-se, diretamente, ao Senhor

v. 6: o salmista fala sobre o Senhor, dirigindo-se a seu ouvinte ${ }^{7}$

Contudo, por mais bonita que seja a forma do Salmo 23, para a maioria dos leitores-ouvintes, provavelmente, as dimensões teológicas sejam a razão principal para o sucesso dessa oração. As pessoas sentem-se confortadas pelo que está sendo afirmado na parte do conteúdo. Por isso, é preciso descrever, com exatidão, o que se diz a respeito do Senhor nesse texto. Como o pastor divino atua em favor do ser humano? Qual é o comportamento correspondente, da parte do homem, à atuação do Senhor? Afinal, por mais que o princípio da gratuidade prevaleça em Deus, prevê-se, na religião do Antigo Israel, a corresponsabilidade de quem foi criado e eleito pelo Senhor bondoso e fiel.

\section{O título (v. 1a)}

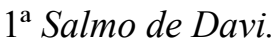

O Salmo 23 faz parte do primeiro "Saltério de Davi" (Sl 3-41), sendo que os salmos atribuídos a este rei formam cinco grupos no livro dos

${ }^{5}$ Erich Zenger, Der Psalter als biblisches Buch, p. 334.

${ }^{6}$ Ao analisar Sl 118, Martin MARK (Meine Stärke und mein Schutz ist der Herr, p. 500) destaca o poema como "obra artística de três dimensões": a primeira dimensão aparece quando o texto é lido de forma "linear"; a segunda dimensão ganha presença ao se insistir na leitura concêntrica ou "palindrômica"; e a terceira dimensão torna-se visível ao se descobrir "as citações e alusões a outros textos sagrados" que o Salmo traz para dentro de si.

${ }^{7}$ Sobre a estrutura concêntrica, cf. Erich Zenger, Psalm 23, p. 152. 
Salmos (Sl 3-41; 51-72; 101-103; 108-110; 138-145). ${ }^{8}$ Com isso, o leitor ou ouvinte é convidado a imaginar as palavras do Salmo 23 como salmo de ou para Davi, personagem acompanhada de diversas conotações simbólicas. Davi, originalmente, era um pastor de gado miúdo (cf. 2Sm 16,11). Mais tarde, porém, recebeu a tarefa de pastorear seu povo (cf. S1 78,71-72). Todavia, logo no início do Salmo 23, o próprio Davi afirma que o Senhor, ou seja, Deus mesmo é seu pastor. O rei insiste no pastoreio divino! Sublinha-se, dessa forma, que a verdadeira liderança pertence ao Senhor, Deus de Israel. A Davi, por sua vez, cabe a tarefa de salmodiar, a fim de proclamar o pastoreio e a hospitalidade do Senhor, único capaz de garantir o bem-estar e a sobrevivência ao homem.

\section{O pastoreio divino na base da justiça (v. 1b-3)}

Após o título, inicia-se a primeira parte do Salmo 23. Nela, o salmista descreve as qualidades do pastoreio do Senhor.

$1 \mathrm{~b} O$ Senhor é meu pastor:

1c não sinto falta de nada.

$2^{\mathrm{a}}$ Faz-me reclinar em verdes pastagens.

2b Conduz-me a águas em lugares de repouso.

$3^{\text {a }}$ Traz de volta minha alma.

3b Guia-me por trilhas de justiça,

3c por causa de seu nome.

Ao ser empregado, em todas as frases, a primeira pessoa do singular, as palavras ganham a característica de um canto individual. O salmista chama, pois, o Senhor de meu pastor (v. 1b). Declara: eu não sinto falta de nada (v. 1c). Afirma: o Senhor me faz reclinar (v. 2a), me conduz (v. 2b) e me guia (v. 3b) Além disso, formula: traz de volta minha alma (v. 3a).

No mais, o salmista fala sobre o Senhor, apresentando a atuação do Deus de Israel sempre na terceira pessoa do singular. Testemunha que o pastor divino faz reclinar, conduz, traz de volta e guia, e tudo isso por causa de seu nome. Quer dizer: na primeira parte do poema (v. 1b-3c), o salmista não se dirige, diretamente, a seu Deus, mas fala sobre o Senhor.

Além disso, quem canta aqui salmodia para quem o ouve. Ou seja: dirige-se a um público anônimo, a fim de dar seu testemunho pessoal. Quer dizer: o salmista, com o qual o leitor talvez queira se identificar, conta o que o Senhor está fazendo ou já fez para ele.

${ }^{8}$ Cf. Erich Zenger, Das Buch der Psalmen, p. 353. 
Observando o conteúdo do Salmo 23, percebe-se o seguinte: o salmista começa com a criação de uma imagem que apresenta o Senhor como pastor (cf. também Gn 48,15 e S1 80,2). A frase $O$ Senhor (é) meu pastor (v. 1b) ganha destaque tanto por sua brevidade - apenas duas palavras no texto hebraico! como por ser uma frase nominal, a qual, no hebraico, dispensa o verbo auxiliar. Exclusivamente "o pastoreio do Senhor, ou seja, a sensação de sentir-se guardado na proximidade agradável e sossegadora dele é o assunto aqui, e não a distinção entre o Senhor como pastor e possíveis outros pastores". ${ }^{9}$ Daqui para frente, o Salmo 23 concentra-se justamente na descrição do pastoreio do Deus de Israel. Neste sentido, "a frase nominal - O Senhor: meu pastor -, ao descrever um estado ou uma situação, ganha função de um lema, sendo que seu conteúdo será desdobrado e ilustrado no decorrer do salmo". ${ }^{10}$

No Antigo Israel, o trabalho do pastor é descrito como uma luta árdua e, às vezes, dramática, a fim de garantir a permanência do rebanho. Basta lembrar as palavras que Jacó dirige a Labão, seu sogro: Eis que são vinte anos que eu estou contigo. Tuas ovelhas e tuas cabras não abortaram. E não comi nenhum carneiro de teu gado miúdo. Não fiz chegar um animal despedaçado a ti, mas eu o compensava. Procuravas de minha mão o que fora furtado de mim durante o dia e o que for furtado de mim à noite. Durante o dia, o calor me comeu e, à noite, o frio. E meu sono fugiu de meus olhos (Gn 31,38-40). Com outras palavras: a vida do pastor não pode ser caracterizada como algo romântico. Pelo contrário, trata-se de um trabalho exigente e perigoso.

No caso do Salmo 23, a imagem do pastor, aparentemente, limita-se a quem lida com gado miúdo, pois somente este tipo de pastor anda com seu rebanho, à procura de verdes pastagens (v. 2a) e águas em lugares de repouso (v. 2b). Entrementes, é preciso observar o uso do plural na apresentação das localidades. Quer dizer: o pastor do gado menor é transeunte. De época em época, transmigra, fazendo o rebanho mudar de pasto. As trilhas, mencionadas em v. 3b, lembram os caminhos estreitos na região montanhosa, onde o gado menor sabe se equilibrar, por mais perigoso que seja. Até certa época no verão, pastor e rebanho ficam ali, pois encontram suficiente pastagem. Após a colheita, porém, descem para os vales. Na época da maior seca, o gado precisa alimentar-se do restolho. Em princípio, pastor é gado são até bem-vindos entre os agricultores sedentários, uma vez que os animais fertilizam, com seus excrementos, os campos. Além disso, surge um intercâmbio e uma

\footnotetext{
${ }^{9}$ Augustin R. Müller, Psalm 23,1 und der identifizierende Nominalsatz, p. 151.

${ }^{10}$ Augustin R. Müller, Psalm 23,1 und der identifizierende Nominalsatz, p. 152.
} 
troca interessante de produtos entre os pastores transeuntes e os agricultores sedentários. Ao contrário de ovelhas e cabras, o gado maior anda muito pouco, pois logo sente falta de água. Muito menos saberia equilibrar-se em trilhas não niveladas (cf. $\operatorname{Pr} 4,26$; Is 26,7).

Sobre si mesmo, por sua vez, o salmista afirma: Não sinto falta de nada (v. 1c). A frase chama a atenção do leitor por vários motivos. É a única vez na primeira unidade literária (v. 1b-3) que o Senhor não é o sujeito da frase. Ou seja: a ênfase está sobre o ser humano, presente como sujeito oculto no verbo que aparece na primeira pessoa do singular. Da mesma forma, o significado da raiz verbal - sentir falta de algo ou carecer - refere-se, em princípio, ao ser humano (cf. Dt 15,18; Is 32,6; Ez 4,17; Pr 13,25). Não se encontra, pois, nenhuma referência na Bíblia Hebraica, onde tal verbo seja usado para descrever um animal necessitado. Mais ainda: a frase Não sinto falta de nada tem caráter de resumo antecipado. Com apenas duas palavras em hebraico, prevalece, outra vez, a brevidade. Assim, v. 1c acompanha bem v. 1b em sua função de servir como lema.

A ideia da ausência de qualquer carência, necessidade ou falta de bens é trabalhada também em S1 34,11. Afirma-se ali que aqueles que buscam o Senhor, em vez de tornarem-se indigentes e passarem fome, não sentem falta de bem nenhum. Da mesma forma, S1 8,6, ao promover sua reflexão antropológica, sublinha a seguinte característica do Senhor em relação ao ser humano: Deixaste lhe faltar pouco em relação aos deuses! Resumindo: indigência, necessidade ou falta de bem-estar, em princípio, contradizem a vontade do Deus de Israel. Resta, no entanto, descobrir quais são as trilhas indicadas pelo Senhor, a fim de que todos possam dizer: Não sinto falta de nada.

O salmista segue com a descrição das razões pela ausência da falta de bens. Com isso, volta a "aplicar a terminologia rica da linguagem pastoril ao Senhor". ${ }^{11}$ O enfoque concentra-se agora no que o pastor de Israel (cf. S1 80,2) oferece a seu rebanho, sendo que, na perspectiva individual do Salmo 23, o rebanho se reduz a um animal. Neste sentido, o cantor descreve, de um lado, os alimentos básicos que o pastor divino disponibiliza: pastagens verdes (cf. Ez 34,14), ou seja, prados com erva nova (v. 2a) e água, ou melhor, água em lugares de repouso, ou seja, num ambiente que oferece descanso(v. 2b). De outro lado, o salmista deixa claro que os alimentos se tornam acessíveis por causa da atuação favorável do Senhor, ou seja, é o pastor divino quem conduz

${ }^{11}$ Bernd Janowski; Ute Neumann-Gorsolke, Der "gute Hirte und seine Herde", p. 87. 
(v. 2b) rumo a lugares que oferecem fartura e bem-estar. Da mesma forma, é o pastor divino quem $f a z$ o animal, respectivamente, a pessoa representada pelo animal reclinar-se (v. 2a; cf. Ez 34,15), sendo que o conduziu, anteriormente, a tal lugar de repouso.

Em v. 3, continua a linguagem metafórica e o tema da condução. Com a brevidade já observada em v. 1b.c, o salmista afirma agora: Minha alma traz de volta (v. 3a). A raiz verbal voltar pode ganhar, na conjugação hebraica, o significado de trazer de volta ou fazer voltar, no sentido de recolher o que antes estava disperso (cf. Ez 39,27). ${ }^{12}$ Além disso, existe a possibilidade, no texto hebraico, de a expressão minha alma substituir o pronome pessoal me. Compreendido assim, v. 3a ganha maior plasticidade, a qual se perderia caso se optasse pela tradução: Minha alma restaura. Outra vez: o que é dito em v. 3a pode se referir tanto ao animal como à pessoa representada pelo animal, o que é típico para a linguagem metafórica. Em todo caso, o Senhor é pastor que traz de volta o que ou quem estava perdido.

$\mathrm{Na}$ frase final de seu testemunho inicial (v. 1b-3), o salmista, de um lado, dá continuidade a sua reflexão sobre o pastor divino. Apresenta um terceiro ambiente. Após as pastagens verdes (v. 2a) e os lugares de repouso com água (v. 2b), surgem agora as trilhas (v. 3b). Mais tarde, o vale escuro (v. 4a) completará esta lista. Todas essas localidades ajudam a criar a imagem do pastor e de seu rebanho, por mais que um animal não seja mencionado expressamente. No mais, o salmista afirma agora: é o Senhor quem me guia (v. 3b). É interessante observar o paralelismo que se forma com os dois verbos anteriores: veja a sequência conduzir em v. $2 \mathrm{~b}$, trazer de volta em v. 3a e guiar em v. 3b. Aliás, o que o cantor no Salmo 23 afirma de forma individual, S1 77,21 diz sobre Deus numa perspectiva comunitária: Guiaste teu povo como um rebanho.

De outro lado, entra agora um conceito-chave na reflexão de quem canta as palavras do Salmo 23. Afirma-se, pois, que, pelas trilhas da justiça (v. 3b), o Senhor pretende trazer a pessoa de volta (v. 3a) ao bem-estar. Este bem-estar inclui a disponibilidade dos alimentos necessários - veja as pastagens verdes em v. $2 \mathrm{a}$ e as águas em v. $2 \mathrm{~b}$ - e o descanso - veja o repouso em v. 2b. Enfim, busca-se uma realidade em que o ser humano não sente falta de nada (v. 1c). Contudo, seja sublinhado outra vez - e isso em sintonia com as palavras do Salmo 23 - que o caminho de salvação rumo a uma situação satisfatória de bem-estar passa pelas

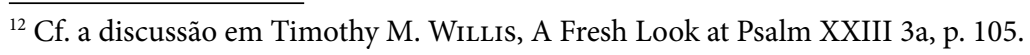


trilhas da justiça. Pois é com sua justiça que o Senhor quer guiar o ser humano (Sl 5,9), sendo que pastoreia segundo o direito (Ez 34,16).

Enfim, o discurso do cantor no Salmo 23 culmina no assunto da justiça. Com isso, o salmista promove a sabedoria profética da religião do Antigo Israel. Afinal, sabe-se que as trilhas do bem são justiça, direito e retidão (Pr 2,9) e que justamente estas são as trilhas do Senhor (S1 17,5), trilhas que pingam gordura $(\mathrm{S} 165,12)$. Mais ainda: Deus propõe-se até a aplainar a trilha do justo (Is 26,7; Pr 5,21), no sentido de lhe ensinar o caminho da sabedoria e fazê-lo andar nas trilhas da retidão (Pr 4,11).

Além do mais, a palavra trilha permite imaginar "um caminho, no qual alguém já andou anteriormente, ou seja, os rastros como resultado visível deste andar". ${ }^{13}$ Isso vale também para a questão da justiça. Trata-se de um caminho que o povo de Deus conhece, desde as origens de sua história. E esse caminho se transformou em ensino. Basta ler o ensino por excelência - a Torá, ou seja, o Pentateuco -, sobretudo, as tradições do êxodo, inclusive os mandamentos de Deus, sendo que estes últimos se propõem a transformar a experiência de libertação em um projeto jurídico. Feliz quem sente prazer com este ensino (cf. Sl 1,2). ${ }^{14}$ Pois é aqui que se descobre a natureza do Senhor, marcada pela insistência na inversão do destino dos pobres (cf. Sl 113). ${ }^{15}$ E é por causa disso que Israel, sempre de novo, volta à casa do Senhor (cf. v. 6), uma vez que o Templo e a cidade de Jerusalém encontram sua tarefa mais sublime na promoção da justiça (cf. S1 122). ${ }^{16}$

Finalmente, o cantor no Salmo 23 fecha a primeira parte de seu poema insistindo no nome do Senhor (v. 3c) como modelo decisivo de justiça. Afinal, o Deus de Israel santificou seu nome quando libertou seu povo da escravidão no Egito (cf. Lv 22,31-33). Neste sentido, o nome de Deus pretende garantir que o Senhor sempre será quem está $(\mathrm{Ex} 3,14)$ com os carentes e necessitados, ou seja, com quem sente falta do que é necessário para uma sobrevivência digna. Quem reza no Salmo 23 realçará tal presença salvadora do Senhor ainda mais ao afirmar: Tu estás comigo! (v. 4c).

No mais, o nome de Deus, além de trazer o Senhor presente, destaca a característica principal da ação dele. Pois é por causa de seu nome (v. 3c), ou seja, de acordo com o significado de seu nome, que o Senhor é pastor

\footnotetext{
${ }^{13}$ Markus Philipp Zehnder, Wegmetaphorik im Alten Testament, p. 414.

${ }^{14}$ Cf. Matthias Grenzer, Caminhos de justos e perversos.

${ }^{15}$ Cf. Matthias Grenzer, Ação inversora do destino dos pobres.

${ }^{16}$ Cf. Matthias Grenzer, As tarefas da cidade.
} 
(v. 1b). Neste sentido, o primeiro testemunho do salmista (V. 1b-3) encontra-se moldurado por elementos que fazem de Deus o foco de atenção: $o$ Senhor é pastor (v. 1b) e ele age por causa de seu nome (v. 3c). Ou, observada a forma do texto: a expressão seu nome em v. $3 \mathrm{c}$ faz referência à presença do nome do Senhor - o tetragrama - em v. $1 b .{ }^{17}$ Os elementos centrais (v. 1c-3b), por sua vez, levam a atenção aos que creem neste Deus, sendo descrito, mais concretamente, o que o Senhor faz em benefício deles. ${ }^{18}$

\section{O conforto da presença protetora do Senhor (v. 4)}

A perspectiva do poema muda em v. 4. O salmista dirige-se agora, de forma direta, ao Senhor (v. 1b), em vez de se pronunciar sobre o pastor divino (v. 1b-3c). Ou, com outras palavras: a imagem e a experiência do pastoreio exercido pelo Senhor transformam-se em "alocução comprometedora de oração". ${ }^{19}$ As duas conjunções hebraicas, traduzidas como mesmo que, "marcam", logo no início da segunda unidade literária do poema, "uma cesura". ${ }^{20}$ Elas introduzem uma oração subordinada que traz uma situação específica à mente, na qual há de se provar que o pastoreio do Senhor realmente existe.

$4^{\mathrm{a}}$ Mesmo que ande por um vale escuro,

$4 \mathrm{~b}$ não temo mal algum,

$4 \mathrm{c}$ porque tu estás comigo.

4d Teu bastão e teu cajado:

4e eles me confortam.

Ao empregar o pronome pessoal da segunda pessoa do singular, o cantor do Salmo 23 chama o Senhor agora de $t u$ (v. 4c). Da mesma forma, os sufixos pronominais nos substantivos teu bastão e teu cajado (v. 4d), traduzidos como pronomes possessivos, confirmam essa nova perspectiva. De outro lado, continua prevalecendo a perspectiva individual no que se refere ao salmista. Os verbos andar e temer são apresentados na primeira pessoa do singular. Igualmente, o sufixo pronominal da primeira pessoa do singular, acrescentado à preposição comigo e ao verbo confortam-me, faz referência ao mesmo "eu".

\footnotetext{
${ }^{17}$ Cf. Siegfried Mittmann, Aufbau und Einheit des Danklieds Psalm 23, p. 11.

${ }^{18}$ Cf. Yair MAzor, Psalm 23, p. 417.

${ }^{19}$ Klaus Seybold, Poetik der Psalmen, p. 218.

${ }^{20}$ Cf. Erich Zenger, Mit meinem Gott überspringe ich Mauern, p. 228.
} 
Indo ao encontro do conteúdo do discurso, outro elemento completa a imagem composta do mundo pastoril. De repente, é preciso andar por um vale escuro. As trilhas anteriormente mencionadas (v. 3b) já levam o pensamento do ouvinte-leitor à região montanhosa, onde os caminhos se estreitam. $\mathrm{O}$ vale escuro suscita ainda mais a lembrança dos desfiladeiros e barrancos íngremes na região desértica de Judá. Ali "a luz do dia chega somente de forma atenuada e a sombra da noite se estende cedo". ${ }^{21}$

Contudo, dois instrumentos são muito úteis na travessia perigosa de um vale escuro. De um lado, o pastor usa o bastão. Trata-se, conforme a iconografia do Antigo Oriente, de uma clava mais curta, bastante resistente e mais pesada, sobretudo, no lado oposto à empunhadura, tendo, muitas vezes, semelhança a uma maça. Tal bastão serve como arma, em especial para defender-se a si mesmo ou para defender um membro do rebanho contra um animal selvagem. O cetro dos reis no Antigo Oriente imita a forma do bastão, sendo que, em hebraico, se trata da mesma palavra. De outro lado, o cantor do Salmo 23 lembra o cajado. Este é mais comprido e o pastor pode apoiar-se nele. Mais ainda: é com o cajado que conduz o rebanho. Às vezes, o pastor toca, com o cajado, as rochas no caminho, a fim de que os animais sejam guiados pelo som. Outras vezes, afasta com o cajado um arbusto. Em uma situação de emergência, o cajado estendido pode tornar-se uma ajuda bem-vinda, para que um animal, ao se apoiar nele, supere um desnível. ${ }^{22}$

Mais ainda: embora a imagem do ambiente pastoril prevaleça em v. 4, o vale escuro ou, mais literal ainda, o vale da escuridão provoca ainda outras associações. A terra de treva e escuridão, pois, é o lugar da morte, rumo a qual a pessoa caminha e da qual não volta, lugar sem ordem (Jó 10,21s; 38,17). Neste sentido, em hebraico, a palavra escuridão espelha até o significado de sombra da morte. Além disso, o motivo da escuridão serve, na cultura do Antigo Israel, para ilustrar um lugar marcado pela opressão (Is 9,1.3) e pela presença de prisioneiros de ferro e miséria (S1 107,10.14). Por último, vale lembrar que o deserto, terra de estepes e barrancos - região pela qual o Senhor fez caminhar seu povo, quando o fez subir do Egito, durante o êxodo - é tido como terra de aridez e escuridão, sendo que o ser humano, normalmente, não atravessa ou habita tal lugar $(\mathrm{Jr} 2,6)$.

\footnotetext{
${ }^{21}$ Siegfried Mittmann, Aufbau und Einheit des Danklieds Psalm 23, p. 9.

${ }^{22}$ Cf. imagens e explicações em Othmar KeEL, Die Welt der altorientalischen Bildsymbolik und das Alte Testament, p. 208s.
} 
Resumindo: a escuridão "simboliza a ameaça da existência". ${ }^{23}$ Onde a sobrevivência da pessoa não se encontra mais garantida - por causa de um poder opressivo, da miséria ou da própria morte-, a realidade torna-se escura. Contudo, o Salmo 23 afirma, junto à tradição religiosa do Antigo Israel, que o Senhor está com quem passa por essa situação, sendo que tal realidade não foge do poder dele. Afinal, o Senhor pode transformar a luz em escuridão (Jr 2,16), mas também a escuridão em manhã luminosa (Am 5,8).

Neste sentido, o povo de Deus, de acordo com sua experiência histórica coletiva ou individual -, testemunha e cultiva a esperança de que a ação divina possa ocorrer de acordo com as circunstâncias dadas. O justo perseguido, cuja voz se escuta no Salmo 23, espera poder verificar o companheirismo confortante do Senhor (v. 4e), ao andar num vale escuro. Eis a sua razão por não querer temer mal algum (v. 4b).

Cabe ainda observar dois paralelismos que, mais facilmente, podem ser vistos ou ouvidos em hebraico. Em v. 1b, o Senhor é chamado de meu pastor. O substantivo mal em v. $4 \mathrm{~b}$ revela uma escrita e pronúncia semelhante. ${ }^{24}$ Trata-se, portanto, de um paralelismo na base de uma aliteração. No mais, duas expressões verbais ganham certa semelhança por apresentarem a mesma forma e por ser repetida a negação: confira não sinto falta em v. 1c e não temo em v. 4b. ${ }^{25}$ Surge, com isso, a impressão de que a forma do texto apoia o conteúdo. A primeira parte do Salmo 23, formada por duas unidades literárias menores (v. 1b-3c e v. 4a-e), encontra-se, de certa forma, moldurada pelos paralelismos existentes entre v. 1 e v. 4 . No mais, a metáfora complexa do mundo pastoril, ao perpassar toda a primeira parte do Salmo 23, confere coesão literária a v. 1-4.

\section{A ceia festiva promovida pelo anfitrião divino (v. 5)}

Na segunda parte do Salmo 23 (v. 5-6), é trabalhada outra imagem: o bom anfitrião e a hospitalidade que este oferece. Novamente, duas pequenas unidades literárias formam o trecho. Na primeira delas (v. 5), é mantida a direção do discurso da unidade literária anterior (v. 4). O salmista dirige-se diretamente ao Senhor, dizendo-lhe como experimenta a ação hospitaleira dele como anfitrião divino.

\footnotetext{
${ }^{23}$ Siegfried Mittmann, Aufbau und Einheit des Danklieds Psalm 23, p. 10.

${ }^{24}$ Cf. Mitchell Dahood, Stichometry and Destiny in Psalm 23,4, p. 417.

${ }^{25}$ Cf. Siegfried Mittmann, Aufbau und Einheit des Danklieds Psalm 23, p. 11.
} 


\section{$5^{\text {a }}$ Preparas uma mesa diante de mim,}

$5 \mathrm{~b}$ oposta aos que me agridem.

5c Oleaste minha cabeça com perfume.

5d Minha taça é transbordante.

O primeiro elemento da hospitalidade descrita no Salmo 23 refere-se à alimentação. $\mathrm{O}$ salmista imagina o Senhor preparar uma mesa diante dele (v. 5a), de acordo com a cultura do Antigo Oriente, onde se cultiva "a expectativa de anfitriões, em suas mesas, providenciarem comida para seus hóspedes". ${ }^{26}$ Uma série de narrativas bíblicas ilustra este costume. Ao apresentar a visita misteriosa a Abraão, a narrativa, no caso, reserva um espaço significativo à preparação e à colocação dos alimentos diante dos visitantes (cf. Gn 18,1-8). ${ }^{27}$ De forma semelhante, também Melquisedec (Gn 14,18), Ló (Gn 19,1-3), Raguel (Ex 2,20), o homem de Belém (Jz 19,4-8), o imigrante de Gabaá (Jz 19,21), Booz (Rt 2,14), a viúva de Sarepta (1Rs 17,8-16) e a mulher de Sunam (2Rs 4,8-10) celebram sua hospitalidade, oferecendo comida a seus hóspedes.

Mais ainda: da mesma forma que o Senhor preparou uma mesa para seu povo no deserto $(\mathrm{S} 178,19)$, no tempo em que este, após a saída do Egito, caminhou rumo à liberdade na terra prometida, ele alimenta agora o salmista, novamente em meio a circunstâncias adversas e num ambiente hostil. Agressores, pois, se opõem a quem dialoga no Salmo 23 com o Senhor (v. 5b). O termo agressor refere-se a pessoas que causam aflições a outros. De forma insensata (S1 74,23), encolerizam-se (S1 7,7), favorecendo pranto (S1 6,7s), escárnio (S1 31,12), insulto (S1 42,11), afronta, vergonha e opróbrio (S1 69,20). Os que afligem os demais podem ser conterrâneos, mas também invasores estrangeiros que se fazem presentes em meio aos encontros no santuário (S1 74,3s). Em todo caso, oferecer proteção e segurança ao hóspede - ou seja, conforto em meio a uma situação perigosa (cf. v. 4) -, é outra tarefa do anfitrião, sobretudo, à noite. Exemplifica isso o comportamento de $L o ́$ (Gn 19,4-11), de Raab (Js 2), do imigrante velho de Gabaá (Jz 19) e de Jó (Jó 31,32).

Ao avançar com sua descrição da hospitalidade do Senhor, o salmista traz, como terceiro elemento, a ideia de sua cabeça ter sido oleada com perfume (v. 5c; cf. Lc 7,46). "Na ocasião de uma refeição festiva, pois, gordura perfumada é colocada sobre a cabeça dos hóspedes, sendo que ela derrete

\footnotetext{
${ }^{26}$ Andrew E. Arterbury e William H. Bellinger, Jr., "Returning" to the Hospitality of the Lord, p. 391.

${ }^{27}$ Veja Matthias Grenzer, Três visitantes (Gn 18,1-15), p. 61-73.
} 
com o calor do corpo, espalhando seu cheiro (S1 133,2)". ${ }^{28}$ Composto por diversos aromas e tendo como base o azeite, o perfume oleoso refresca a pele da cabeça, favorecendo, desse modo, o repouso (v. 2b) e a recuperação do alento (v. 3a), devolvendo vigor ao corpo inteiro (cf. Sl 92,11). Neste sentido, é bom que, além dos vestidos brancos, não falte perfume sobre a cabeça do homem $(\mathrm{Ecl} 9,8)$ e que o perfume não caracterize apenas o bem-estar dos nobres (cf. Am 6,6).

$\mathrm{O}$ quarto elemento da hospitalidade oferecida pelo anfitrião divino consiste na taça transbordante (v. 5d). O hóspede é convidado a participar da abundância dos bens do hospedeiro. Em hebraico, pois, o adjetivo transbordante traz a conotação de beber muito e até embriagar-se. Mais ainda: ao pensar que a taça transborde de vinho, favorece-se, então, a alegria e o bem-estar do coração (S1 104,15; Ec1 9,7) de quem se acomoda numa casa alheia. Por consequência, surge o resultado de que "o Senhor não conforta apenas o salmista em tempos difíceis, para que o salmista não sinta medo, mas que a presença de Deus é tão profunda que Deus oferece até regozijo neste momento". ${ }^{29}$

Enfim, "a imagem do trato principesco do Senhor com quem reza em v. 5, com os três aspectos básicos da comida, bebida e unção, pertence, no Antigo Oriente, à tradição real". ${ }^{30}$ Textos revelam como reis oferecem este tipo de ceia festiva. ${ }^{31}$ Seja citada a inscrição do rei assírio Asarhaddon (680-669 a.C.):

"Os grandes e o povo de meu país: fiz todos se assentarem em mesas festivas, com refeição e muita comida. Fiz jubilar seu coração, molhei seu interior com vinho branco e vinho tinto. E fiz suas cabeças molharem-se com perfume precioso". ${ }^{32}$

Também as imagens do Antigo Oriente apresentam este tipo de cena, sendo que "a taça se torna o símbolo de tais refeições". ${ }^{33}$ No Salmo 23,

\footnotetext{
${ }^{28}$ Othmar KeEL, Die Welt der altorientalischen Bildsymbolik und das Alte Testament, p. 311.

${ }^{29}$ Dennis D. Sylva, The Changes of Images in Ps 23,5.6, p. 114.

${ }^{30}$ Hermann Spieckermann, Heilsgegenwart, p. 271.

${ }^{31}$ Veja os paralelos extrabíblicos a v. 5-6 em Michael L. BARré e John S. Kselman, New Exodus, Covenant, and Restoration in Psalm 23, p. 104-114.

${ }^{32}$ Tradução segundo Rykle Borger, Die Inschriften Asarhaddons König von Assyrien, §27A, VI 49-53.

${ }^{33}$ A respeito das tradições do Antigo Oriente, veja as informações em Kathrin EHLERs, "JHWH ist mein Becheranteil", p. 48-49.
} 
por sua vez, o Senhor, Deus de Israel, assume a função do rei e oferece os bens de forma abundante a seu hóspede, sendo que este último, como justo perseguido, se encontra, neste momento, ameaçado em sua sobrevivência por enfrentar opositores.

\section{O encontro repetido com o Senhor na casa dele (v. 6)}

Como no início da oração (v. 1b-3c), o salmista dirige-se, também no final de seu discurso (v. 6), a quem o ouve, dando destaque à atuação do Senhor com ele. Dois paralelismos reforçam a conexão entre as unidades literárias no início e no final do poema, tornando visível uma moldura em torno da parte central (v. 4.5), onde o salmista fala diretamente a seu Deus. De um lado, observa-se que a oração começa com a menção do nome de Deus, sendo que o tetragrama é traduzido aqui como Senhor (v. 1b). Pela segunda vez, o nome de Deus aparece somente no final do poema (v. 6c). De outro lado, a raiz verbal voltar ganha presença na primeira e última parte da oração, ou seja, nas frases Minha alma traz de volta (v. 3a) e Voltarei à casa do Senhor (v. 6c). No mais, v. 6 tem caráter de conclusão e resumo. A linguagem metafórica cede lugar à linguagem abstrata. O salmista contempla sua vida inteira, focando sua ida repetida ao templo como movimento desejado.

$6^{\mathrm{a}}$ Apenas bondade e fidelidade me perseguem,

$6 \mathrm{~b}$ todos os dias de minha vida.

6c E voltarei à casa do Senhor,

6d ao longo dos dias.

Pressupondo que o tema da hospitalidade continue em v. 6 - veja a imagem da casa -, surge "um contraste irônico: em vez de inimigos perseguirem o viajante, bondade e graça fazem isso". ${ }^{34} \mathrm{Em}$ geral, pois, o verbo perseguir indica uma situação em que alguém é agarrado (S1 71,11), gratuitamente (S1 119,161), por agressores (S1 119,157). Quer dizer: o mais robusto (S1 142,7), em vez de praticar a fidelidade, persegue o oprimido e pobre (S1 109,16), fazendo a falsidade prevalecer (S1 119,86). Não obstante, existe também a experiência contrária. É possível perseguir o bem (S1 38,21) e, com isso, a paz (S1 34,15).

Todavia, quem levanta sua voz no Salmo 23 traz, no final de sua reflexão, dois conceitos abstratos à reflexão, sendo que estes carregam e condensam o sentido do texto. Após ter mencionado a justiça em v. 3b, o salmista faz agora os termos bondade e fidelidade ganharem a atenção dos ouvintes.

\footnotetext{
${ }^{34}$ Andrew E. Arterbury e William H. Bellinger, Jr., "Returning" to the Hospitality of the Lord, p. 392.
} 
O conceito bondade lembra um dado primário da religião do antigo Israel: o Senhor é bom e faz o bem (S1 119,68; 125,4). Tal benfeitoria quer favorecer o homem e se concretiza no ensino bom que o Senhor faz sair de sua boca (S1 119,72), quando promove seus bons julgamentos (S1 119,39) e revela sua retidão ao povo (S1 25,8). Além disso, o Senhor, em sua bondade, está disposto a perdoar (S1 86,5) e a fazer o homem experimentar sua bondade, em especial, quando a terra dá seu produto (S1 85,13), quando a alma faminta se enche com o que é bom (S1 107,9) e quando o homem pode sentir que sua juventude está sendo renovada (Sl 103,5).

O conceito de fidelidade indica a graça divina, no sentido de o homem poder experimentar a solidariedade do Senhor. Aliás, os três conceitos indicam possíveis traduções da mesma palavra hebraica. Seguindo os paralelismos, a ideia da fidelidade divina traz as características principais do Senhor à memória: sua misericórdia, compaixão e paciência (S1 51,3; $69,17 ; 86,15 ; 103,4.8 ; 109,12 ; 145,8)$, sua capacidade de realizar maravilhas (S1 107,8.15.21.31), de salvar (S1 6,5; 13,6; 31,17; 85,8; 98,3; 109,26; $119,41)$ e de redimir (S1 44,27; 130,7), de ver a opressão que atinge o homem (S1 31,8), de libertar a alma do homem da morte e fazê-lo viver na fome (S1 33,18; 86,13; 109,21), de oferecer-lhe proteção (S1 36,8; 59,17; 144,2), opondo-se à agressores e inimigos (S1 143,12). No mais, a fidelidade divina enche a terra por Deus amar justiça e direito (S1 33,5) e fazer o homem aprender suas prescrições e ordens (S1 119,64.88.124.149.159). Neste sentido, a fidelidade divina se manifesta como retribuição (S1 62,13), mas também como perdão (S1 86,5), sendo ela expressão da aliança concluída com seu povo (S1 89,29; 106,45). O maior número de paralelismos indica, porém, a correspondência da fidelidade divina à verdade, ou seja, à lealdade presente no Senhor (S1 25,10; 26,3; 36,6; 40,11s; 57,4.11; 61,8; 69,14; 85,11; 86,15; $88,12 ; 89,3.15 .25 .34 .50 ; 92,3 ; 98,3 ; 100,5 ; 108,5 ; 115,1 ; 117,2 ; 138,2)$.

Resumindo: a criação, a libertação de Israel da escravidão no Egito, o presente da terra e a possibilidade de todos poderem comer - tudo é resultado da graça divina (cf. Sl 136). Afinal, o Senhor pratica a fidelidade (Sl 18,51; 109,16), sendo fiel e bom (S1 25,7; 107,1; 118,1.29; 136,1), justamente como é declarado por quem reza no Salmo 23.

Igualmente, a volta à casa do Senhor ao longo dos dias (v. 6c.d) é resultado da graça divina. Ou seja: primeiramente, a possibilidade de alcançar tal casa é uma experiência da fidelidade do Senhor (S1 5,8). No segundo momento, o interior desta casa, ou seja, a parte interior do templo, oferece a 
oportunidade de meditar a fidelidade divina (S1 48,10; 138,2). E, por terceiro, é nesta casa que o fiel se sacia com a gordura ali presente e bebe da torrente dos prazeres de Deus, sendo tudo isso fruto da fidelidade valiosa do Senhor, uma vez que o manancial da vida está com ele (S1 36,8-10). ${ }^{35}$

\section{Considerações finais}

Quem emite sua voz no Salmo 23 se encontra ameaçado em sua sobrevivência. Observando, pois, a sequência das orações no livro bíblico dos Salmos, há a impressão de que, "a partir do Salmo 22, quem reza no Salmo 23 se apresenta como um pobre", ${ }^{36}$ pois no Salmo 22 guarda-se o grito de quem nem se sente mais homem, mas verme ( $\mathrm{Sl} 22,7)$. Não obstante, como miserável, faz a experiência de que Deus não menospreza, nem tem aversão à miséria do oprimido (S1 22,25a.b); pelo contrário: escuta o grito de quem está sendo curvado e humilhado (S1 22,25d).

O Salmo 23 mesmo revela apenas poucos pormenores da vida de quem se manifesta aqui. No caso, uma das afirmações sobre o Senhor - Minha alma traz de volta! (v. 3a) - leva o leitor a imaginar "as inquietações precedentes de quem fala assim; antes das pastagens verdes, existiram, então, períodos ásperos; era preciso que a força de vida fosse restaurada". ${ }^{37}$ Talvez o Salmo 23 seja até "o canto de um israelita que, diante de seus perseguidores, encontrou refúgio no templo de Jerusalém"; neste sentido, "a assistência do pastor divino não fortalece aqui quem já é forte ou quem já é dominante na sociedade, mas se dirige aos fracos e perseguidos, os quais temem não apenas por seu direito mas também por sua simples existência". ${ }^{38}$

Contudo, o Salmo 23 sonha com a inversão do destino de quem é agredido e, por isso, se tornou carente nos mais diversos sentidos. Nem é difícil vislumbrar os elementos que fazem parte da concretização deste sonho apre-

\footnotetext{
${ }^{35}$ As consoantes do termo hebraico $e$ voltarei podem ser lidas também com outra vocalização, pressupondo que se trate do verbo sentar/assentar-se/morar. Desta forma, algumas traduções já compreenderam v. 6c como Meu sentar/meu morar está na casa do Senhor. Contudo, por causa do paralelismo criado na base da presença dupla do verbo voltar (v. 3a.6c) e por causa de o Salmo 24, ao seguir o Salmo 23, acolher o desejo final de quem pretende voltar ao templo e apresentar uma liturgia de entrada no santuário, a leitura Voltarei à casa do Senhor ao longo dos dias (v. 6c.d) é preferível. Cf. Ernst Axel Knauf, Psalm XXIII 6, p. 556.

${ }^{36}$ Frank Lothar Hossfeld e Erich Zenger, "Wer darf hinaufziehen zum Berg JHWHs?", p. 181.

${ }^{37}$ Michael Goulder, David and Yahweh in Psalm 23 and 24, p. 466.

${ }^{38}$ Willy Schоттroff, Psalm 23, p. 48.51.
} 
sentado. Trata-se de um processo, pois, aparentemente, "o poema descreve uma viagem" (v. 1b-4e) "que culmina na chegada ao templo" (v. 5-6). ${ }^{39}$ Quais são, no entanto, as etapas?

Para começar, o nome do Senhor (v. 3b) quer garantir que, na base da justiça divina (v. 3c), se chegue a uma situação marcada pela presença dos bens materiais absolutamente necessários para a sobrevivência, a fim de que a pessoa não sinta falta de nada (v. 1c). Ou seja: tudo começa com a ausência de fome e sede (v. 2). Além disso, a pessoa, em meio às diversas ameaças, deve ter a possibilidade de experimentar proteção e condução (v. 4). Mais ainda: um bem-estar maior marca o destino, sendo que, na forma de mesas preparadas, gente perfumada e taças transbordantes (v. 5), a fartura possa ser experimentada numa ceia festiva. Tudo culmina, por sua vez, no momento em que a pessoa volta à casa do Senhor, pois sabe que a bondade e fidelidade deste Deus se fizeram presentes (v. 6).

Todavia, salmodiando (v. 1a), ou seja, falando diretamente ao Senhor e falando sobre o Senhor aos outros, se cultiva a confiança em Deus e a esperança de que o futuro possa ser bom para quem ainda anda pelo vale escuro (v. 4a).

\section{Referências bibliográficas}

ALONSO-SCHÖKEL, Luís; CARNITI, Cecília. Salmos I (Salmos 1-72). Tradução, introdução e comentário. (Grande Comentário Bíblico). São Paulo: Paulus, 1996.

ARTERBURY, Andrew E.; BELLINGER Jr., William H., Returning“" to the Hospitality of the Lord. A Reconsideration of Psalm 23,5-6. In: Biblica 86 (2005) 387-395.

BARRÉ, Michael 1.; KSELMAN, John S. New Exodus, Covenant, and Restoration in Psalm 23. In: Carol L. Meyers; M. O'Connor. The Word of the Lord Shall Go Forth (Festschrift David Noel Freedman). Winona Lake, Indiana: Eisenbrauns, 1983, p. 97-127. (Coleção: American Schools of Oriental Research Special Volume Series No. 1).

BORGER, Rykle. Die Inschriften Asarhaddons Königs von Assyrien. (AfO.B 9). Graz: 1956.

DAHOOD, Mitchell. Stichometry and Destiny in Psalm 23,4. In: Biblica 60 (1979) 417-419.

${ }^{39}$ Mark S. SMITH, Setting and Rhetoric in Psalm 23, p. 63. 
EHLERS, Kathrin. „JHWH ist mein Becheranteil“. Zum Bechermotiv in den Psalmen 16; 23 und 116. In: Andreas Michel; Hermann-Josef Stipp (ed.). Gott Mensch Sprache. (Festschrift Walter Gross). (Arbeiten zu Text und Sprache im Alten Testament 68). St. Ottilien: EOS, 2001, p. 45-63.

GOULDER, Michael. David and Yahweh in Psalm 23 and 24. In: Journal for the Study of the Old Testament 30 (2006) 463-473.

GRENZER, Matthias. Caminhos de justos e perversos. Exegese do Salmo 1. In: Atualidade Teológica 38 (2011) 335-348.

GRENZER, Matthias. Ação inversora do destino dos pobres. Um estudo do Salmo 113. In: Atualidade Teológica 36 (2010) 441-452.

GRENZER, Matthias. As tarefas da cidade. Exegese do Salmo 122. In: Afonso M.L. Soares; João Décio (org.). A fé na metrópole. Desafios e olhares múltiplos. (Teologia e Universidade). São Paulo: Paulinas, 2009, p. 265-281. GRENZER, Matthias. Três visitantes (Gn 18,1-15). In: Revista de Cultura Teológica, v. 57, a. 2006, p. 61-73.

HOSSFELD, Frank Lothar; Zenger, Erich. „Wer darf hinaufziehen zum Berg JHWHs?“. Zur Redaktionsgeschichte und Theologie der Psalmengruppe 15-24. In: Georg Braulik; Walter Gross; Sean McEvenue (org.). (Festschrift Norbert Lohfink). Freiburg: Herder, 1993, p. 166-182.

HUNZIKER-RODEWALD, Regine. Hirt und Herde. Ein Beitrag zum alttestamentlichen Gottesverständnis. (Beiträge zur Wissenschaft vom Alten und Neuen Testament 155). Stuttgart, Kohlhammer, 2001.

JANOWSKI, Bernd. Konfliktgespräche mit Gott: Eine Anthropologie der Psalmen. Neukirchen-Vluyn, ${ }^{2} 2006$.

JANOWSKI, Bernd; NEUMANN-GORSOLKE, Ute. Der, gute Hirte“ und seine Herde. In: Bernd Janowski; Ute Neumann-Gorsolke; Uwe Glessner. Gefährten und Feinde des Menschen. Das Tier in der Lebenswelt des alten Israel. Neukirchen-Vluyn: Neukirchener, 1993, p. 85-89.

KEEL, Othmar. Die Welt der altorientalischen Bildsymbolik und das Alte Testament. Am Beispiel der Psalmen. Göttingen: Vandenhoeck \& Ruprecht, ${ }^{5} 1996$.

KNAUF, Ernst Axel. Psalm XXIII,6. In: Vetus Testamentum 51 (2001) 556.

MARK, Martin. Meine Stärke und mein Schutz ist der Herr. Poetologischtheologische Studie zu Psalm 118. (Forschung zur Bibel 92). Würzburg: Echter, 1999.

MAZOR, Yair. Psalm 23: The Lord is my Shephard - Or is He my Host? In: Zeitschrift für die Alttestamentliche Wissenschaft 100 (1988), 416-420. 
MITTMANN, Siegfried. Aufbau und Einheit des Danklieds Psalm 23. In: Zeitschrift für Theologie und Kirche 77 (1980) 1-23.

MÜLLER, Augustin R. Psalm 23,1 und der identifizierende Nominalsatz. In: Sigurdor Örn Steingrímsson; Kristinn Ólason (ed.). Literaturund sprachwissenschaftliche Beiträge zu alttestamentlichen Texten. (Festschrift Wolfgang Richter). (Arbeiten zu Text und Sprache im Alten Testament 83). St. Ottilien: EOS, 2007, p. 137-153.

OEMING, Manfred. Das Buch der Psalmen. Psalm 1-41. (Neuer Stuttgarter Kommentar Altes Testament 13/1). Stuttgart: Katholisches Bibelwerk, 2000. SCHOTTROFF, Willy. Psalm 23. Zur Methode sozialgeschichtlicher Bibelauslegung. In: Idem. Gerechtigkeit lernen. Beiträge zur biblischen Sozialgeschichte. (Organizado por: Frank Crüsemann e Rainer Kessler, junto a Luise Schottroff). (Coleção: Theologische Bücherei, 94, Altes Testament). Gütersloh: Kaiser; Gütersloher Verlagshaus, 1999.

SPIECKERMANN, Hermann. Heilsgegenwart. Eine Theologie der Psalmen. (Forschungen zur Religion und Literatur des Alten und Neuen Testaments 148). Göttingen: Vandenhoeck \& Ruprecht, 1989.

SEYBOLD, Klaus. Poetik der Psalmen. Stuttgart, Kohlhammer, 2003.

SMITH, Mark S. Setting and Rhetoric in Psalm 23. In: Journal for the Study of the Old Testament 41 (1988) 61-66.

SYLVA, Dennis D. The Changing of Images in Ps 23,5.6. In: Zeitschrift für die Alttestamentliche Wissenschaft 102 (1990) 111-116.

WILLIS, Timothy M. A Fresh Look at Psalm XXIII 3A. In: Vetus Testamentum 37 (1987) 104-106.

ZEHNDER, Markus Philipp. Wegmetaphorik im Alten Testament. Eine semantische Untersuchung der alttestamentlichen und altorientalischen Weg-Lexeme mit besonderer Berücksichtigung ihrer metaphorischen Verwendung. (Beihefte zur Zeitschrift für die alttestamentliche Wissenschaft 268). Berlin: Walter de Gruyter, 1999.

ZENGER, Erich. Der Psalter als biblisches Buch. Alte und neue Wege der Psalmenauslegung am Beispiel von Psalm 23. In: Religionsunterricht an höheren Schulen 49 (2006) 324-337.

ZENGER, Erich. Das Buch der Psalmen. In: Erich Zenger e outros. Einleitung in das Alte Testament. Stuttgart, Kolhammer, ${ }^{7} 2008$. [Em português, existe a tradução da primeira edição deste livro: Zenger, Erich. Introdução ao Antigo Testamento. São Paulo, Loyola, 2003]. 
ZENGER, Erich. Psalm 23. In: Frank-Lothar Hossfeld; Erich Zenger. Psalmen I. Psalm 1-50. (Die Neue Echter Bibel: Kommentar zum Alten Testament mit der Einheitsübersetzung 29). Würzburg: Echter, 1993, p. 152-156.

ZENGER, Erich. Mit meinem Gott überspringe ich Mauern. Einführung in das Psalmenbuch. Freiburg: Herder, 1991.

Matthias Grenzer

Professor na Faculdade de Teologia da PUC-SP

Artigo Recebido em 22/08/2011

Artigo Aprovado em 26/03/2012 